\title{
Enhancing learning and teaching in the tertiary music studio through reflection and collaboration
}

\author{
This paper reports on a multi-institutional project using reflection and \\ collaboration to enable one-to-one music teachers to improve their professional \\ skills and foster deep learning in music students. The benefits of reflection and \\ collaboration in student learning and teacher development are reported on in \\ depth within higher education. Less researched is their relevance to the one-to- \\ one tertiary music context. This project comprised several initiatives around \\ professional development activities for teachers and reflective exercises for \\ students. The outcomes indicate the potential for the transformative approaches \\ of reflection and collaboration to improve student learning outcomes in one-to- \\ one tertiary music settings. This would appear to be dependent on two factors: \\ students receiving support and guidance to reflect in such a way that enhances \\ their learning outcomes; and teachers receiving support and guidance on how to \\ foster students' reflective capabilities. One recommendation from the study is \\ that greater professional development opportunities in these areas are made \\ available to one-to-one music teachers.
}

Keywords: transformative learning; reflective practice; student engagement; studio music teaching; higher music education; tertiary music education

Contemporary educational theory has shifted from positioning students as passive knowledge-recipients, towards allowing students to become active participants with agency over their learning processes (e.g. Biggs \& Tang, 2011; Lysaker \& Furuness, 2011). While this is highlighted within higher education literature at large, conservatoires, and more specifically one-to-one instrumental and vocal tuition, have been slower to respond to this shift. While there are several pedagogical models that have been investigated for their potential to support the $21^{\text {st }}$ century tertiary music student - such as small group lessons (Daniel, 2004; 2008), ensembles (Harrison, O’Bryan, \& Lebler, 2013), team teaching (Wollner \& Ginsborg, 2011) and collaborative learning (Gaunt \& Westerlund, 2016) - one-to-one instruction currently serves as the primary method by which tertiary music students receive their practical skills and performance-based training globally (AEC, 2010). Ongoing evaluation of this model is 
therefore required in order to ensure the approach to one-to-one tuition best meets the needs of students.

'Transformative learning' (Mezirow, 1991; Taylor \& Cranton, 2012) provides a useful framework for thinking about how to optimise one-to-one learning and teaching within the tertiary music studio context. Based on constructivist assumptions about learning (that meaning is created by individuals, and developed through dialogue with others), transformative learning acknowledges the benefits of learners becoming autonomous, responsible thinkers, and recognises the value of both collaborative and reflective practices as supporting this aim. It positions the teacher as facilitator, drawing the student into discourse and critical reflection, and providing opportunities for learners to confirm, establish, or transform their own perspectives around learning (Mezirow, 1997). With a transformative approach, it is possible for the music studio setting to support the development of students' autonomy through student-teacher collaboration, as opposed to controlling students' behaviour or encouraging dependency on the teacher (Carey \& Grant, 2016; Reeve, Deci \& Ryan, 2004; Reeve \& Jang, 2006; see also Gaunt, 2010; 2011).

In order for one-to-one music tuition to align more closely with the studentdriven pedagogies noted in transformative learning, professional development of instrumental and vocal teachers is needed. Reflection has been noted in education as a valuable vehicle for such professional development (Brookfield, 1998; Cranton \& King, 2003; Moon, 2013). While some might view reflecting as 'self-indulgent navel gazing', in practice it 'is often seen as the bedrock of professional identity' (Finlay, 2008, p. 2). The one-to-one tradition, however, has no structured mechanism for questioning its own premises: it has been argued that 'one-on-one teaching does not inspire us to question how we teach' (Chronister, 2005, p.8). This, at least in part, is likely due to an absence of a shared sense of professional knowledge of one-to-one pedagogy. Researchers have thus drawn attention to the need for studio music teachers' professional knowledge to be made more accessible and transparent, variously describing the one-to-one setting as a 'culture of concealment' (Carey et al., 2013), a 'black box' (Rostvall \& West, 2003), and a 'secret garden' (Young, Burwell \& Pickup, 2003). In this context, collaborative professional development opportunities would foster shared understanding of standards of professional practice and make excellent teaching practices observable, as well as enabling a sense of community of practice for teachers. 


\section{Enhancing learning and teaching: A multi-institutional approach}

This project builds on the findings of an extensive pilot study (2011-2013), which tracked pedagogical practices at one Australian conservatoire with the aim of capturing students' and teachers' intentions, perceptions, aspirations and expectations of one-toone lessons in a conservatoire (sources de-identified for review purposes). Using a collaborative inquiry approach, outlined in depth in a previous publication (deidentified), the pilot project revealed the potential for transformative pedagogical approaches within the one-to-one context. It suggested the need for one-to-one teachers to engage in ongoing critical reflection of their pedagogical practices; for institutions to explore broadening the scope and nature of one-to-one instrumental and vocal tuition; and for institutions to support collaborative and reflective learning strategies among and between both students and teachers. This project acts on those recommendations and expands the focus to investigate multiple institutions.

Adopting a collaborative inquiry approach to this research, this article focuses on four participating institutions whose initiatives involved one-to-one tuition: three in Australia and one in the UK. The project team consisted of four female senior academics in the area of research and scholarship of learning and teaching and one male instrumental performance lecturer. Initially, the team gathered to discuss the possible strategies and underlying approaches of reflection and collaboration. Given the unique contexts for each institution (for example, with lessons at one institution taking place off campus, with teachers rarely crossing paths), project team members were then responsible for devising an initiative to suit their institutional context; these were subsequently carried out under the guidance of the project team leader. This approach enabled data from a range of initiatives to be generated, which was provided to the host institution for analysis. Analysis and reporting was carried out by a research team at the host institution, again under the guidance of the project leader.

The institutional contexts and project activities are first briefly described (see also Table 1), before outlining the analysis process. The article then turns to a discussion of outcomes.

\section{Institution 1}

Institution 1 has approximately 900 students across undergraduate and postgraduate levels. For this project, four one-to-one teachers invited their students to participate in a 
guided reflective process. The ten participating students were asked to video-record a specified lesson, then subsequently watch the video, and respond to a set of questions eliciting reflections on the learning processes, lesson objectives, and teacher-student interactions. They then selected a five-minute portion of the video to watch together with their teacher at their next lesson, and audio recorded the resulting discussion with their teacher, focusing on questions about the learning process. Data sourced from this initiative include the video segments, students' written reflections, recorded discussions, and interviews with participating teachers.

\section{Institution 2}

Institution 2 has 192 students enrolled in music performance courses. Individual lessons occur off-campus with teachers who are outsourced. For this project, 16 one-to-one teachers participated in two professional development workshops which were conducted within an existing staff development program. Drawing on outcomes of the pilot study, workshop activities included facilitated peer reflection sessions, presentations by experts, group discussions, and focus sessions reflecting on videoed lessons (deidentified for review purposes). Following the workshop, participants were invited to complete formal evaluation forms and/or email their feedback and reflections on the workshop.

\section{Institution 3}

Institution 3 is an independent conservatoire in the UK, with 570 undergraduate and 345 postgraduate music students, and a strong international reputation. To allow for flexibility of scheduling, the initiative undertaken here involved four pairs of teachers who participated in a reflective dialogue about their teaching. The dialogue was prompted by self-selected videos of lessons and facilitated by a mentor. It was anticipated that the initiative would provide opportunities for newer staff to form useful collegial links within the school and benefit from the insights of more experienced teachers. It was also hoped that senior colleagues may find their own teaching invigorated by the reflective and discursive process. The eight participating teachers met on three occasions over a six month period and gave verbal feedback on their experiences during their final mentoring session for this project. 


\section{Institution 4}

Institution 4 has approximately 600 undergraduate students and over 200 postgraduate students. The project initiatives here built upon previous activities, and encompassed staff development workshops and student reflective activities. Teachers $(n=17)$ voluntarily participated in a series of workshops across the 2015 academic year, led by both internal and visiting guest facilitators. The workshops, which aimed to increase teachers' awareness of approaches to learning and teaching, provided an opportunity for teachers to reflect on and discuss teaching with colleagues. Workshop activities were similar to those implemented at Institution 2. Upon completion of the workshops, teachers were asked to complete a formal evaluation form and were invited to email more detailed reflections. Four teachers also participated in partnered reflections outside of workshops, in a similar vein to Institution 3.

A third initiative was also conducted in this institution, this time focussing directly on students' learning. The aim was to encourage students to engage deeply with their learning and reflect on their learning outcomes. Students at this institution are required to complete a reflective journal as part of their performance studies course. The journal captures student reflections on a range of activities and experiences associated with their performance studies, including one-to-one lessons, concerts, workshops and master classes. 
Table 1: Overview of project initiatives

\begin{tabular}{|c|c|c|c|}
\hline & Initiative & Participants & Timeline \\
\hline Institution 1 & $\begin{array}{l}\text { Student-teacher } \\
\text { reflections aided by } \\
\text { video recorded } \\
\text { lesson segment }\end{array}$ & $\begin{array}{l}\text { Ten undergraduate } \\
\text { students } \\
\text { Four studio teachers }\end{array}$ & June 2015 \\
\hline Instituion 2 & $\begin{array}{l}\text { Two professional } \\
\text { development } \\
\text { workshops }\end{array}$ & $\begin{array}{l}\text { Sixteen studio } \\
\text { teachers }\end{array}$ & $\begin{array}{l}\text { April 2016, } \\
\text { September } 2016\end{array}$ \\
\hline Institution 3 & $\begin{array}{l}\text { Paired reflective } \\
\text { dialogue facilitated } \\
\text { by a mentor }\end{array}$ & $\begin{array}{l}\text { Eight studio } \\
\text { teachers }\end{array}$ & $\begin{array}{l}\text { February to July } \\
2016\end{array}$ \\
\hline Institution 4 & $\begin{array}{l}\text { 1) Two } \\
\text { professional } \\
\text { development } \\
\text { workshops } \\
\text { 2) Paired teacher } \\
\text { reflective dialogue } \\
\text { 3) Student } \\
\text { reflective journal }\end{array}$ & $\begin{array}{l}\text { 1) Seventeen studio } \\
\text { teachers } \\
\text { 2) Four studio } \\
\text { teachers } \\
\text { 3) Five second year } \\
\text { undergraduate } \\
\text { students }\end{array}$ & $\begin{array}{l}\text { 1) May 2015, } \\
\text { September } 2015 \\
\text { 2) March } 2015 \\
\text { 3) May } 2015\end{array}$ \\
\hline
\end{tabular}

As the descriptions of the initiatives highlight, each activity involved reflection and collaboration, either student-teacher or teacher-teacher (see note at the end of this paper).

\section{Data analysis}

Members of the research team carried out several iterations of data analysis, both independently and as a team. Data from each initiative was first analysed discretely. Institutions that employed a similar initiative (with workshops in both Institutions 2 and 4, and paired reflective dialogues in Institutions 3 and 4) were then triangulated. The themes of reflection and collaboration that underpinned the project served as startingpoints for deductive analysis. Several sub-themes emerged inductively, and these serve as the structure for the following discussion of outcomes. 


\section{Teacher reflection and collaboration}

The outcomes presented in this section suggest that formalising the process of reflection on teaching by teachers leads to insights that in turn improve teaching practices.

Perhaps less common in this context is the finding that shared reflection (reflecting with other teachers on teaching practices) is also beneficial, affording teachers the opportunity to expand their approach to reflection itself and to share critical insights on teaching that deepen their understanding of their own practices.

\section{Teacher workshops}

Participation in professional development workshops gave teachers the opportunity for structured and facilitated reflections on their teaching, alongside their colleagues. The responses from workshop participants were strongly positive, with 13/14 respondents of one event (Institution 4), 6/7 respondents of a second event (Institution 4), and 14/16 respondents at a third event (Institution 2) expressing in writing that they were beneficial to improving teaching practices. Specifically, teachers stated that they gained a heightened awareness of their current teaching practices $(n=16)$ and discovered new pedagogical insights to inform their future teaching $(n=29)$. Individual comments highlighted specific benefits such as being able to reflect more broadly on their teaching methodologies, discuss teaching strategies, finding new solutions to challenges faced, avoiding habitual patterns of teaching, and putting the needs of the student first, each of which informs best practice moving forwards. Some emailed reflections include:

The most thought-provoking exercise I think I've ever been through... I found it incredibly worthwhile. [Institution 2, Teacher 1, in relation to a peer reflection activity, workshop 3]

One important thing ... was the opportunity, for the first time in a supportive setting, to self-reflect on how my teaching comes across at an in-depth level and how that can help me to formulate a strategy for a teaching approach ... that is tailor made to each student. [Institution 4, Teacher 1]

It's easy to get in a rut and so any chance to stop and reflect is welcome. Personally I have already felt renewed energy and freshness in the past week back at regular teaching. [Institution 4, Teacher 2] 
These comments indicate the value that these individuals placed on these initiatives, and suggest potential for such workshops to foster meaningful teacher reflections. A longitudinal study would be necessary to determine whether this positive impact led to sustainable changes in teaching long-term.

These workshops also highlighted the fact that collaborative reflections need not be discipline-specific in order to be useful. On the contrary, as Watkins and Scott (2012, xiv) posit, teachers of unrelated instruments can 'benefit from considering each other's approach' by providing the opportunity to step back from specific instrumental issues of technique and to focus on the broader implications of their teaching strategies. Despite initial reluctance from some participants, several teachers realised this in these workshops. One commented:

I was remembering this in light of [my] negative feedback regarding pairing of different instrumental disciplines, such as me with [teacher], when in fact we all need to take another step back and view the whole through a much more holistic lens - at least I do! [Institution 2, Teacher 2]

While this teacher's expectations were transformed through her experiences, there was an isolated instance whereby a teacher did not perceive any benefits through attending workshops. This teacher's emailed feedback on the workshops provides insight into why this was the case:

The activities we were offered to undertake did not feel natural or comfortable to me and I did not feel that I have learned a great deal. [Institution

4, Teacher 3, Email feedback, May 2015]

Evidently, sharing reflective insights into teaching practices was something this teacher neither expected nor was comfortable with in this setting. It is possible that misperceptions about the nature of the event influenced her ability or willingness to participate. Despite a reluctance to fully engage with the workshop, this teacher also commented, 'Staff discussions are the most rewarding events and should be continued.' Her concerns, then, seem to have arisen not from the collaborative nature of peer interactions, but rather from prior expectations about the workshop. Other researchers have observed, in other contexts, that teachers may be wary of professional development processes if they are seen as evaluative and externally imposed (A. Bell \& Mladenovic, 2008) or if professional autonomy is seen as under attack (Gosling, 2002). 
For those who reported reaping benefits from attending, workshops cultivated further collaborative discussions with peers following from the event. One teacher commented,

I can honestly say (... unexpectedly) that follow-up discussions have been taking place in hallways and offices regarding what was unearthed in those sessions... I have personally had chats with a few participants in recent weeks about how we felt those sessions had affected our teaching practices. [Institution 4, Teacher 3, Email feedback, May 2015]

This indicates the increased sense of collegiality that such interactions can create (M. Bell, 2005), and that this has the ability to fuel continued informal collaborative and reflective practice for those involved. Further supporting this suggestion is A. Bell and Mladenovic's (2008) study involving peer reflections. They also found that such activities led teachers to aspire to change their teaching practices, and that 'a year later, tutors are still commenting that they found the exercise to be valuable and have been extolling its benefits to new tutors' (p. 747).

Overall, insights gained from teachers' participation in workshops strengthened their awareness of the connection between student learning outcomes and lesson interactions, and informed their future pedagogical decisions. This supports the notion that sharing professional knowledge amongst teachers is beneficial for the profession (Purser, 2005) as it can result in improved teaching practice and transformation of perspectives around learning and teaching (M. Bell, 2005).

\section{Paired teacher-teacher collaborations}

As with the workshops, initiatives involving paired teacher discussions and reflections also proved to be effective in increasing transparency of one-to-one teaching practices (Institution 3, $\mathrm{n}=8$, Institution 4, $\mathrm{n}=4$ ). Teacher feedback indicates that these interactions led to new insights into their teaching $(n=5 / 12)$, impacted on their future teaching choices $(n=4 / 12)$, and that they valued the opportunity to discuss their teaching with a peer $(n=11 / 12)$. The new insights teachers referred to particularly centred on their communication styles in lessons, noting the benefits of a transformative approach to teaching, which includes a more open and discursive style of communication, in contrast to a transfer approach, which is largely didactic (Carey et al., 2013a). Specifically, one teacher noted that his peer encouraged student reflections more than he 
did, and felt inspired to trial different reflective tools with his students, such as videoing lessons (Institution 3, Teacher 1). Another teacher reported becoming more aware of opportunities to give students space to learn, as opposed to doing the learning for them (Institution 3, Teacher 2). A third teacher, observing a peer asking students a lot of questions, was keen to do more of this in their own teaching (Institution 3, Teacher 3). Each of these insights promised to inform future teaching, highlighting the power of collaboration to improve practice.

While one institution team member reported observing that teachers 'have a tendency to become self-conscious or defensive', this was not evident in peer interactions. One teacher explained that trust came easily because everyone involved had 'signed up' for that kind of conversation (Institution 3, Teacher 4). Teacher 5 commented that he initially expected to feel intimidated, but this did not eventuate; the peer reflective activities were designed to be non-judgemental and developmental, as opposed to evaluative (A. Bell \& Mladenovic, 2008).

\section{Teacher responses to student reflections}

As with teacher reflections, student reflections, when shared with teachers, also had the ability to inform future teaching and thus enhance student learning outcomes. While the emphasis was initially on student reflections as a means for students to increase their engagement with their learning, it also resulted in teachers reflecting on their own practices and arriving at new insights into their teaching. One teacher commented:

Initially I felt [the written reflections were] an exercise to benefit the students. But... it has made me a little bit more thoughtful in about how I present information or questions to students during lessons... It influenced me in a way that then extended to all of my other students who weren't participating in the study. I'm being more conscious with everybody. [Institution 1, teacher 1]

In institution 4, teachers had the opportunity to read their students' 'Performance Studies Portfolios' (PSPs), which included responses to questions designed to encourage students to reflect on their learning (for detailed descriptions of the PSPs, see source de-identified for review purposes). The student reflections within prompted teachers to reflect on their communication styles and provided an opportunity to reflect 
on their approaches to students' learning and to understand the learning that is taking place. Some emailed insights include the following:

This clearly has an influence on the way I need to teach, as opposed to the way I think I teach. [Institution 4, Teacher 5]

It helps my own teaching for me to see what can be improved and made clearer for students. [Institution 4, Teacher 6]

It's a great form of feedback on what's working towards supporting their learning. [Institution 4, Teacher 7]

It is incredibly valuable... I am able to gain better insight into the way they are thinking and learning, which of course helps me moderate and develop the ways in which I communicate with them... Too often we (I) assume that things are happening and quite often I discover that they are not! Conversely, I discover that some students are doing far more than I realise, which also gives me the opportunity to discuss these things with them. [Institution 4, Teacher 8] It is clear here that reading their students' reflections was a catalyst for these teachers to reflect on their teaching practices in a way that informed future practice. However, not all teachers had read their own students' journals, having marked PSPs written by other students. The danger here is that journals remain isolated from the teaching and learning context to which they relate (that is, the students' one-to-one lessons). A more effective approach would be for teachers to engage with their own students' journals and use them to reflect on their teaching.

Overall, regardless of the catalyst - whether workshops, paired teacher discussions, or student reflections - teachers reported benefiting from the opportunity to reflect on their teaching practices, gaining an increased awareness of their pedagogical choices and the ability to choose informed strategies. Furthermore, the development of a community of practice alleviated the isolating effects of teaching by providing opportunities for teachers to build relationships with colleagues and increased transparency of teaching practices in such a way that extended to the professional growth of others. 


\section{Student reflections}

One of the aims of the project was to explore ways of encouraging music students to become more independent and to take a greater level of ownership over their learning in the one-to-one context. Reflective learning was a key component in achieving this aim, as reflection encourages students to make connections between new ideas and their existing knowledge, to continuously monitor their learning, and to address gaps in their understanding at an earlier stage (Hübner, Nückles \& Renkl, 2010). This has the ability to develop students' capacity for higher order thinking (Coulson \& Harvey, 2013), can provide new perspectives on practice (Glazer, Abbott \& Harris, 2004), and may lead to sustained learning outcomes (Ryan \& Ryan, 2013). The insights presented in this section indicate that reflective learning has the ability to enhance student learning, but also that this is dependent on the reflective capabilities of the student and the level of guidance and support given by teachers.

\section{Student reflections on videos}

In institution 1, students selected a five-minute segment of a video recorded lesson to discuss with their teacher, outside of their usual lesson time. Thorgersen (2014) argues that such an approach can contribute to altering the student-teacher dynamic to that of 'critical friends', allowing students to formulate their response to the video in advance and to engage with their teacher in a meaningful and reflective manner. While eight of the ten students talked freely with their teachers, two students displayed reluctance to share their thoughts. This may have been due to the initiative's 'contrived setting' (Institution 1, Teacher 1) when compared to the familiar context of the one-to-one lesson. It was also clear that some students were unsure how to respond to the questions posed by their teachers, perhaps because they were more familiar with interactions that resembled transfer pedagogy (Carey et al., 2013b). While they cannot be taken as indicative of lesson interactions at large, the students' chosen video segments illustrated students' limited ownership of learning in lessons, with many students often allowing the teacher to direct and guide activities. Teachers need to gauge a student's readiness to reflect critically and meaningfully, and a certain level of maturity is needed from the student in order to reflect in this way (Merriam et al., 2012). As some participating students were in their first year of their degree, this level of maturity may well have still been developing. In these instances, some teachers appeared to be unsure about how to 
elicit deep reflections from their students. As one teacher commented:

Not all students know how to reflect... They didn't really know how to respond, and they lacked confidence in what to say... Some students, when you leave things totally open-ended, they're just drowning. They just need really clearly defined parameters... Others you can ask, 'what do you think of that? How does that compare to what you were hoping to play?' and they respond really well. [Institution 1, Teacher 1]

Students need support in learning to reflect (Ryan \& Ryan, 2013; Coulson \& Harvey, 2013), and this was evident here. It is also apparent that teachers need support in learning to foster students' reflective abilities. Teacher 1 commented that he was unsure of how to get students to the point where they would know how to answer reflective questions. This was also evident in some other teachers' approaches. At times, teachers used the interaction as an opportunity to provide further instructive feedback on the student's playing being viewed in the video. Perhaps students' discomfort or inability to openly share their thoughts led teachers to take the role on for themselves. Coulson and Harvey (2013) suggest that a level of openness and self-analysis is required for reflection to lead to valuable learning, and so it is possible that these interactions did not benefit the students' learning greatly.

As understanding the processes involved in reflection have been found to help students develop reflective capacities (Ryan \& Ryan, 2013), in retrospect, this initiative may have been more effective had teachers and students received guidance on how to best approach the task, and if teachers were provided with examples of questions to prompt reflections. This was not done so initially, as it was (perhaps unreasonably) expected that teachers would be adept at eliciting reflection from their students. It became clear that teacher professional development in this area would be of benefit. (Team members were subsequently invited to attend an international symposium organised by the team leader, which provided an opportunity for teachers to collaborate and discuss teaching approaches that could strengthen students' reflective abilities and consequent learning outcomes.)

Other teachers involved in this initiative appeared more confident in guiding the reflective process, acknowledging students' responses before building on them with their own thoughts, and prompting deeper insights through further questioning. Being 
persistent (to a point) and employing a sequence of questions can be effective in eliciting from students (Burwell, 2005), and this was evident in these interactions.

Consequently, these students shared reflections readily and appeared more willing to engage. As Burwell argues, 'Effective questioning must be one of the most important ways of eliciting a contribution from students' (2005, p. 204), encouraging students to participate actively in their learning and contributing to creating independent thinkers and learners. The video segments of lessons viewed in these instances highlighted that questioning and support already featured in these teachers' approaches in the studio. These teachers focussed primarily on the thinking of the student, as opposed to the performance outputs. This suggests that students' willingness to share reflective insights into their learning may be, at least in part, dependent on the communication styles of their teachers.

Of the six students interviewed, five commented on the benefit of videorecording their lessons as a way to strengthen their learning, including helping memory of important aspects for practice and discussions in lessons $(n=3)$, having a different perspective on their playing $(n=4)$, and as guidance for practice $(n=3)$. This became a sustainable practice that extended beyond the timeframe of the initiative, as well as to other non-participating students. The team member noted:

Even though this initiative focussed on student-teacher collaboration, students talk. The idea of videoing as a means to improve learning has 'caught on like wildfire' and now everyone is doing it. [Team member 1]

While few music-specific studies have described the use of video as a medium for reflective teaching and learning practice, the use of video has substantial precedent in music research as a means to analyse and describe elements of music lessons (see Gustafson, 1986; Rostvall \& West, 2003; Young et al., 2003; Daniel, 2006; Carey et al., 2013a). Recording has also been noted as valuable for students, including as a way of documenting progress, reflecting critically on their playing, self-assessing musical outputs, and providing a new perspective from which to hear themselves (Daniel, 2001). The use of video is a proven tool for developing reflective practices in education at large (see Derry, 2007; Hollingsworth, 2005), however this has been relatively underresearched within tertiary music tuition. Given the nature of learning an instrument, that is, that most of the learning typically occurs in the practice room in isolation, and the 
potential of video to transform the student-teacher dynamic (Thorgersen, 2014), this warrants further investigation.

\section{Student reflections on their learning}

In considering students' written responses in the aforementioned Performance Studies Portfolios (PSPs), it is evident that critically questioning students through this medium has the potential to enhance reflective practice and learning outcomes and to encourage collaborative discussions within lessons (source de-identified for review purposes). This was particularly evident when questions were specific and required deep levels of thinking to respond effectively (Hubner, Nuckles \& Renkl, 2010). Students' responses to these questions, in contrast to more broad questions, included evidence of higher levels of cognitive awareness and metacognitive involvement (Hatton \& Smith, 1995).

A focus group was held with five students who had been writing the PSPs for two years, in order to investigate their experiences in writing the journals, the benefits they perceived (if any), and other related insights. All students reported that the PSPs encouraged them to reflect, and three of the five students noted that the process of writing the PSPs helped them to establish a reflective practice routine. The PSPs also encouraged students to think about what they had learned in their lessons, how they improved through their lessons based on certain feedback, and how that could influence their practice through the week. Students particularly commented that more specific questions allowed a greater focus on the process than performance outcomes; this in turn is more beneficial to skill development and autonomous learning (Dweck \& Master, 2012; Zimmerman \& Schunk, 2012).

While teachers noted that the responses in the journals display a range of reflective abilities, overall, they reported seeing an improvement in the quality of student reflections each semester. This supports Ryan and Ryan's (2013) claim that practice and time increase students' reflective abilities. Teachers observed, however, that many students struggle with reflections that go beyond descriptive. One teacher commented, 'As usual, there were some who really understood what they were meant to do, and others whose responses were vague and inadequate' (Institution 4, Teacher 6). This again highlights the need for ongoing support to develop and implement reflective abilities, whether outside of the one-to-one lesson, or within the lessons themselves. 
Given that it was found that the language teachers use impacts on students' abilities to reflect (as previously described), there is potential to leverage student-teacher interactions in one-to-one lessons to cultivate students' reflective skills. As noted previously, teacher collaborations, both in pairs, and in workshops, has the ability to provide new insights into communication styles with students. This - cultivating teachers' abilities to develop students' reflective capacities - is therefore an area worthy of further investigation.

These findings demonstrate that students' participation in reflective activities has the potential to impact positively on their learning, dependent on a student's reflective capabilities. Tertiary music students may not be often afforded the opportunity to reflect so explicitly on their practice and learning. Their reflections were more insightful with guidance or training on how to reflect critically; teachers themselves may also require guidance on how to best provide this support. Furthermore, and importantly, students' shared reflections with teachers provides a valuable opportunity for teachers to gain insights into the learning that is (or is not) taking place, and to reflect on their current and potential teaching practices and choices.

\section{Recommendations and considerations}

This project responded to one recommendation arising from the pilot project: namely, for institutions to support collaborative and reflective learning strategies for both students and teachers, by providing an opportunity for teachers to share ideas and question existing practices, and by prompting students to reflect on their learning. This occurred in various forms in this study, as evidenced in the range of initiatives implemented. One finding of this research is that students require guidance and support to become autonomous and reflective learners, and likewise, that teachers require guidance and support in developing a teaching practice that fosters a transformative approach to teaching and learning.

This project's initiatives saw a modest increase in the number of teachers at participating institutions engaging in professional self-development through research and reflective collaborations, indicating a willingness or readiness to change and develop their practices (Wlodarsky, 2005). Consequently, shared understandings of good practice developed through new insights and innovative teaching practices can 
inform future teaching. This circularity has much potential for having a positive impact on the student experience and learning outcomes, and institutional culture at large.

In this project, teacher professional development through peer collaboration and reflection proved beneficial overall. While it is important for institutions to provide opportunities for this to occur, time will tell whether this can lead to sustainable transformation of practice. A number of questions remain, including: how much support will teachers require in order to take responsibility for their own development; and what are the long-term benefits to student learning outcomes? These are necessary questions to explore if we are to understand both the most beneficial approaches to professional development long-term and more fully the impact of transformative pedagogical approaches on student learning.

Seeking answers to these questions, and providing continued opportunities for pedagogical development, and for institutions, teachers and students to form collaborative relationships, may eventually foster a more strongly reflective learning culture within tertiary institutions. While the focus of this project has been within tertiary institutions, potential also exists for professional development opportunities and reflective and collaborative practices to be adopted by one-to-one music teachers in community-based (non-institutional) studio environments. The principles offered in this paper, if applied more widely, may enhance the learning of many musicians-in-themaking and to encourage best practice across the sector.

\footnotetext{
Note

Readers are invited to access professional development programmes, example activities and relating to the initiatives reported on in this paper by visiting the project website: transformative121.com This website also contains resources for students, teachers and institutions that may be of interest.
}

\section{Acknowledgements}

With thanks to the team members and partner institutions involved in the project and to the staff and students who participated in the research. Thank you to the Office for Learning and Teaching and to the host institution for funding. 


\section{Disclosure statement}

No potential or actual conflict of interest is reported by the authors.

\section{Funding}

This work was supported by the Australian Government Office for Learning and Teaching under Grant ID14-3815. The views in this project do not necessarily reflect the views of the Australian Government Office for Learning and Teaching.

\section{References}

Åkerlind, G. S. 2007. Constraints on academics' potential for developing as a teacher. Studies in Higher Education 32 (1): 21-37. doi:10.1080/03075070601099416

Association of European Conservatoires (2010). Quality assurance and accreditation in higher music education. Amsterdam: Association of European Conservatoires.

Bell, M. 2005. Peer observation partnerships in higher education. NSW, Australia: Higher Education Research and Development Society of Australasia Inc.

Bell, A., \& Mladenovic, R. 2008. The benefits of peer observation of teaching for tutor development. Higher Education 55 (6): 735-752. doi:10.1007/s10734-00790931

Biggs, J., \& C. S. Tang. 2011. Teaching for quality learning at university: What the student does. 3rd ed. Maidenhead, UK: McGraw-Hill/Society for Research into Higher Education \& Open University Press.

Brookfield, S. 1998. Critically reflective practice. Journal of Continuing Education in the Health Professions 18 (4): 197-205. doi:10.1002/chp.1340180402

Burwell, K. 2005. A degree of independence: Teachers' approaches to instrumental tuition in a university college. British Journal of Music Education 22 (03): 199215. doi:10.1017/S0265051705006601

Carey G. \& Grant, C. 2016. Enacting transformative pedagogy in the music studio: A case study of responsive, relational teaching. Paper presented at the ISME CEPROM Seminar, Saint Andrews, Fife, Scotland, 54-63.

Carey, G., Grant, C., McWilliam, E., \& Taylor, P. 2013. One-to-one pedagogy: Developing a protocol for illuminating the nature of teaching in the conservatoire. International Journal of Music Education 31 (2): 148-159. doi:10.1177/0255761413483077 
Carey, G. M., Bridgstock, R., Taylor, P., McWilliam, E., \& Grant, C. 2013.

Characterising one-to-one conservatoire teaching: Some implications of a quantitative analysis. Music Education Research 15 (3): 357-368. doi:10.1080/14613808.2013.824954

Chronister, R. 2005. Principles of teaching and learning: Eight fallacies and eight basic principles of education. In A piano teacher's legacy, edited by E. Darling, 7-28. Kingston, NJ: The Francis Clark Center for Keyboard Pedagogy Inc.

Coulson, D. and Harvey, M. 2013. Scaffolding student reflection for experience-based learning: A framework. Teaching in Higher Education 18 (4): 401-413. doi:10.1080/13562517.2012.752726.

Cranton, P. and King, K. P. 2003. Transformative learning as a professional development goal. New directions for adult and continuing education 98: 31-38. doi:10.1002/ace.97

Daniel, R. 2001. Self-assessment in performance. British Journal of Music Education 18 (03): 215-226. doi:https://doi.org/10.1017/S0265051701000316

Daniel, R. 2004. Innovations in piano teaching: A small-group model for the tertiary level. Music Education Research 6 (1): 23-43. http://dx.doi.org/10.1080/1461380032000182911

Daniel, R. 2006. Exploring music instrument teaching and learning environments: Video analysis as a means of elucidating process and learning outcomes. Music Education Research 8 (2): 191-215. doi:10.1080/14613800600779519

Daniel, R. 2008. Group piano teaching: An alternative strategy for the tertiary teaching of piano. Saarbrucken, Germany: Verlag Dr. Muller.

Derry, S. J. 2007. Guidelines for video research in education: Video research in education. Chicago, IL: NORC at the University of Chicago.

Dweck, C. S. \& Master, A. 2012. Self-theories motivate self-regulated learning. In Motivation and self-regulated learning: Theory, research, and applications, edited by B. J Zimmerman \& D. H. Schunk, 31-52. New York, NY: Lawrence Erlbaum Associates.

Finlay, L. 2008. Reflecting on 'Reflective practice'. Discussion paper prepared for PBLB CETL. PBLB paper, 52.

Gaunt, H. 2010. One-to-one tuition in a conservatoire: The perceptions of instrumental and vocal students. Psychology of Music 38 (2): 178-208. doi:10.1177/0305735609339467 
Gaunt, H. 2011. Understanding the one-to-one relationship in instrumental/vocal tuition in Higher Education: Comparing student and teacher perceptions. British Journal of Music Education 28 (2): 159-179. doi:10.1017/S0265051711000052

Gaunt, H., \& Westerlund, H. (Eds.). (2016). Collaborative learning in higher music education. New York, NY: Routledge.

Glazer, C., Abbott, L., \& Harris, J. 2004. A teacher developed process for collaborative professional reflection. Reflective Practice 5 (1): 33-46. doi:10.1080/1462394032000169947

Gosling, D. 2002. Models of peer observation of teaching. Generic Centre: Learning and Teaching Support Network. 8 (10): 08.

Gustafson, R. I. 1986. Effects of interpersonal dynamics in the student-teacher dyads on diagnostic and remedial content of four private violin lessons. Psychology of Music, 14. 130-139. doi:10.1177/0305735686142004

Harrison, S., O’Bryan, J., \& Lebler, D. (2013). "Playing it like a professional": Approaches to ensemble direction in tertiary institutions. International Journal of Music Education, 31(2), 173-189. doi:http://doi.org/10.1177/0255761413489791

Hatton, N., \& Smith, D. 1995. Reflection in teacher education: Towards definition and implementation. Teaching and teacher education 11 (1): 33-49. doi:http://dx.doi.org/10.1016/0742-051X(94)00012-U

Hollingsworth, H. 2005. Learning about teaching and teaching about learning: Using video data for research and professional development. Paper presented at the Using Data to Support Learning: $10^{\text {th }}$ Conference of the Australian Council for Educational Research (ACER), Melbourne, Australia.

Hübner, S., Nückles, M. \& Renkl, A. 2010. Writing learning journals: Instructional support to overcome learning-strategy deficits. Learning and Instruction 20 (1):18-29. doi:http://dx.doi.org/10.1016/j.learninstruc.2008.12.001.

Knowles, M. S., Holton, E. F., III \& Swanson, R. A. (2011). The adult learner: The definitive classic in adult education and human resource development. 7th ed. London, UK: Elsevier.

Lysaker, J., \& Furuness, S. 2011. Space for transformation: Relational, dialogic pedagogy. Journal of Transformative Education, 9(3), 183-187. doi:10.1177/1541344612439939 
Merriam, S. B., Caffarella, R. S. \& Baumgartner, L. M. 2012. Learning in adulthood: A comprehensive guide. $3^{\text {rd }}$ ed. San Francisco, CA: John Wiley \& Sons.

Mezirow, J. 1991. Transformative dimensions of adult learning. San Francisco, CA: Jossey-Bass.

Mezirow, J. 1997. Transformative learning: Theory to practice. New Directions for Adult and Continuing Education 74: 5-12. doi:10.1002/ace.7401

Moon, J. Reflection in learning and professional development: Theory and practice. New York, NY: Routledge.

Purser, D. 2005. Performers as teachers: Exploring the teaching approaches of instrumental teachers in conservatoires. British Journal of Music Education 22 (3): 287-298. doi:10.1017/S0265051705006546

Reeve, J., Deci, E. L., \& Ryan, R. M. 2004. Self-determination theory: a dialectical framework for understanding sociocultural influences on student. In Big theories revisited, edited by D. M. McInerney \& S. Van Etten, 31-60. Greenwich, CT: Information Age Publishing.

Reeve, J., \& Jang, H. 2006. What teachers say and do to support students' autonomy during a learning activity. Journal of Educational Psychology 98 (1): 209. doi:http://dx.doi.org/10.1037/0022-0663.98.1.209

Renshaw, P. 2009. Lifelong learning for musicians: The place of mentoring. Lectorate Lifelong Learning in Music \& the Arts.

Renwick, J. M., \& Reeve, J. 2012. Supporting motivation in music education. In The Oxford Handbook of Music Education (Vol. 1), edited by G. E. McPherson \& G. Welch, 143-162. New York, NY: Oxford University Press.

Rostvall, A.-L., \& West, T. 2003. Analysis of interaction and learning in instrumental teaching. Music Education Research 5 (3): 213-226. doi:10.1080/1461380032000126319

Ryan, M. \& Ryan, M. 2013. Theorising a model for teaching and assessing reflective learning in higher education. Higher Education Research \& Development 32 (2): 244-257. doi:10.1080/07294360.2012.661704.

Smilde, R. 2009. Musicians as lifelong learners: Discovery through biography. Delft, Netherlands: Eburon B V.

Taylor, E., \& Cranton, P. (Eds.). 2012. The handbook of transformative learning: Theory, research, and practice. San Francisco, CA: Jossey-Bass. 
Thorgersen, C. F. 2014. Learning among critical friends in the instrumental setting. Applications of Research in Music Education 2 (32): 60-67. doi:10.1177/8755123314521032

Watkins, C. \& Scott, L. 2012. From the stage to the studio: How fine musicians become great teachers. New York, NY: Oxford University Press.

Wlodarsky, R. 2005. The professoriate: Transforming teaching practices through critical reflection and dialogue. Teaching and Learning-Grand Forks 19 (3): 156-172. http://www.und.nodak.edu/dept/ehd/journal/summer2005/wlodarsky.pdf

Wollner, C., \& Ginsborg, J. (2011). Team teaching in the conservatoire: The views of music performance staff and students. British Journal of Music Education, 28(3), 301-323. doi:https://doi.org/10/1017/S0265051711000222

Young, V., Burwell, K., \& Pickup, D. 2003. Areas of study and teachingstrategies instrumental teaching: A case study research project. Music Education Research 5 (2): 139-155. doi:10.1080/1461380032000085522

Zimmerman, B. J. \& Schunk, D. H. 2012. Motivation: An essential dimension of selfregulated learning. In Motivation and self-regulated learning: Theory, research, and applications, edited by B. J. Zimmerman \& D. H. Schunk, 1-30. New York, NY: Lawrence Erlbaum Associates. 